\title{
Examinationof Inventory Management in Leather Garments using ISM Technique
}

\author{
K. Koppiahraj, S. Bathrinath, V. G. Venkatesh and S. Saravanasankar
}

\begin{abstract}
The success of a firm will be scaled by the extent to which it meets the customer's intangible demand. Hence an effective inventory management is essential for any manufacturing unit as insufficiencies may result in serious problems. Leather garment industries, being subjective to periodic changes needs to address inventory management as an indispensable issue. Factors like capital investment, insufficient space and poor management will aggregate inventory problems. The intention of the paper is to identify the key concern area which triggers the inventory management problem of leather garments industries by Interpretive Structural Modeling (ISM) technique through an investigative study. MICMAC analysis is used to understand the inter-relationship among the concern areas.
\end{abstract}

Keywords: Inventory management, ISM, MICMAC, Leather garments.

\section{INTRODUCTION}

A manufacturing sectors are under immense pressure in this competitive business environment. To withstand in the competitive market, effective inventory management is necessary. Inventory management, an essential component of supply chain management receives much attention from industrial managers. Inventory management becomes buzzword among industrialist owing to volatile market environment. Inventory control is defined as the management of materials for satisfying customers and minimizing inventory investment with effective utilization of manpower. Inefficient inventory management may bring problems like delay in production and customer dissatisfaction. Adding to this, the rapidly changing customers demand necessitated effective inventory management. Effective inventory management helps to predict the longevity of a product in the market. Proper inventory management ensures uninterrupted supply of goods based on the market demand. The profit/loss of any firm is inarguably decided by the inventory. When most of the finished products remain in the warehouse, it accounts huge loss for the firm. Balanced movements of goods from warehouse to market ensure the success of effective inventory management. Hart et al. [1] indicated that inventory accounts for considerable cost of a firm. So it is necessary to forecast the market demand using effective tools to assist managers in inventory management. Poor forecasting in inventory management may lead to obsolescence. Korpela and Tuominen [2] in their study forecasted inventory using Analytical Hierarchy Process (AHP). Inventories

Revised Manuscript Received on December 05, 2019.

* Correspondence Author

K.Koppiahraj, Department of mechancical engineering, Kalasalingam Academy of research and education, Krishnankoil-626126, India. Email: koppiahraj1993@gmail.com

S.Bathrinath*, Department of mechancical engineering, Kalasalingam Academy of research and education, Krishnankoil-626126, India. Email: bathri@gmail.com

V.G.Venkatesh, Waikato management school, The university of Waikato, Hamilton, Newzealand. Email: vgv1976@gmail.com

S.Saravanasankar, Department of mechancical engineering, Kalasalingam Academy of research and education, Krishnankoil-626126, India. Email: ssaravanasankar@klu.ac.in are essential element for a firm in supply chain management. Angulo et al. [3] insists that inventories accounts $20 \%$ of capital investment. In supply chain management, inventories occur in different stages base material, component, production stage and end product inventories. Practically giving equal attention for all inventories is not possible [4]. On one hand the finished goods inventory should be at the lowest possible while on the other hand it should suffice the market demand. Inventory reduction is considered as better way but not an ideal solution. Inventory management system suggests the managers whether to start production or the available quantity is sufficient [5].

\section{RELEVANT LITERATURES}

Based on inventory level, the production sector decides the quantity of existing products to be produced or will change to other product. The inventory management process differs from industries to industries based on the type of products they are producing. Chan et al. [6] investigated factors influencing effective inventory management in small manufacturing units and identified poor documentation and unskilled employees as the major factors affecting inventory control. Demand forecasting and proper communication about changing customer's desire must be properly conveyed to manufacturing section. Lack of communication and administration are identified as bottleneck in effective inventory management for a manufacturing company in china [7, 8]. The functioning of inventory is dominated by the warehouse capacity. Ishii and Nose [9] in their study also indicated that warehouse capacity influences inventory management. Jones and Riley [10] through their study clarified the myth about inventories. In the study, it was stated that Japanese technique called Just-In-Time (JIT) will eliminate inventory problems. For successful execution of JIT in an industry, high level of commitment from top level management is required. Jonsson and Mattsson [11] assessed the opportunities of implementing novel material planning methods and concluded that factors like size of the industries, location and distribution operation influences the selection of material planning. Koumanakos [12] established the relationship between inventory and top level organization and indicates that high level of inventory results in lower rate of return. A complete review of inventory management in manufacturing sector was studied by Momeni and Azizi [13]. Interpretive Structural Modeling (ISM) is an easy technique for establishing association of different factors of a problem $[14,15]$.

\section{PROBLEM DESCRIPTION}

The framework of the paper is presented in Figure 1.

By reviewing relevant literatures and interaction with industrial experts, following problems were identified after literature survey:

- Inventory control was considered only as a sub-element while evaluating supply chain management.

- Interaction relationship among different factors affecting inventory control was not addressed.

Studies failed to consider inventory problems in leather garments as a serious problem. 


\section{EVALUATION METHODOLOGY}

Key concern areas identified as potential barrier in carrying out inventory management are mutually dependent on each other. Hence a clear establishment about the interrelationship among the key concern area is needed. To establish the association of each factor and their level of influence, ISM modeling technique was used. ISM technique finds its application in different fields - green supply chain management and logistics [16-18]. The following steps are carried out in ISM sequentially:

Step 1: Factors identified as concern areas are detailed.

Step 2: Pair of areas to be scrutinized is recognized by developing connection among the factors identified.

Step 3: A Structural Self-interaction Matrix (SSIM) is constructed. Step 4: Transitivity check is made for the reachability matrix established from step 3. Transitivity, a basic assumption of ISM states that when a factor $\mathrm{X}$ is connected to $\mathrm{Y}$ and $\mathrm{Y}$ is connected to $\mathrm{Z}$, then $\mathrm{X}$ must connected to $\mathrm{Z}$

Step 5: Reachability matrix established is segregated into various stages.

Step 6: From the connections in reachability matrix, a graph is plotted.

Step 7: By using statements in place of factors, the digraph plotted is changed into an ISM paradigm.

\section{CASE STUDY}

ISM methodology discussed above is applied for an investigative study analyzing key concern areas in inventory management of leather garments industry. The case company visited for this study is located in southern India. After discussion with industrial expert and literature survey, ten key concern areas were identified as barrier in inventory management. The ten key concern areas are as follows: 1 . Production system (A1), 2. Effective management tool (A2), 3. Proper Layout design (A3), 4. Unreliable supplier (A4), 5. Lack of coordination (A5), 6. Demand forecasting (A6), 7. Employee training (A7), 8. Customer Service (A8), 9. Export policies (A9), 10. Financial constraint (A10).

\section{A. Structural self-interaction matrix (SSIM)}

Connection among the key concern areas is established depending on literature survey and expert opinion. Four notations are used to highlight the connections among the concern areas:

P: Area $m$ may improve area $n$

Q: Area $n$ may improve area $m$

$\mathrm{R}$ : Area $m$ and $n$ may improve one another

S: Area $m$ and $n$ are unrelated.

The notations $\mathrm{P}, \mathrm{Q}, \mathrm{R}$ and $\mathrm{S}$ used in SSIM are explained under:

(i) Area 1 may improve area 10: indicates that change in production system may improve the financial status related with inventory management. Table 1 shows the relationship between concern area 1 and concern area 10 denoted by 'P'.

(ii) Area 5 may improve area 1: improvement of co-ordination among the worker and top level management will improve production system. Notation ' $Q$ ' represents the relationship between concern area 5 and 1 .

(iii) Area 7 and 1 may improve each other: proper training to employees may result in enhanced production system. Notation ' $R$ ' represents the relationship of concern area 7 and 1 .

(iv) No relationship exists between area 8 and 3: customer service and layout design has no influence over each other. Notation ' $S$ ' represents the relationship between 8 and 3 .

\section{B. Reachability matrix}

The notations in SSIM matrix are replaced by binary matrix of 1 and 0 and initial reachability matrix is obtained. Conditions for using 1 and 0 are detailed below: (i) When $(m, n)$ entry in SSIM is $\mathrm{P}$, then the $(m, n)$ entry in reachability matrix changes into 1 and $(n, m)$ entry turn into 0 .

(ii) When $(m, n)$ entry in SSIM is Q, then the $(m, n)$ entry in reachability matrix changes into 0 and $(n, m)$ entry turn into 1.

(iii) When $(m, n)$ entry in SSIM is R, then the $(m, n)$ entry in reachability matrix changes into 1 and $(n, m)$ entry turn into 1.

(iv) When $(m, n)$ entry in SSIM is S, then the $(m, n)$ entry in reachability matrix changes into 0 and $(n, m)$ entry turn into 0 .

Table 2 shows the initial reachability matrix of concern areas based on the above conditions. Using transitivity, final reachability matrix is obtained and shown in Table 3.

\section{Level partition}

The reachability and antecedent set for each concern area is obtained from the final reachability matrix. From this, the interaction set for all concern areas is obtained. The factor with same reachability and intersection set is given high level in ISM paradigm. The identified high level factor is rejected from other factors. It is visible from Table 4 that areas like lack of coordination (A5), demand forecasting (A6), customer service (A8) and financial constraints (A10) occupies Level I. The step is continued till all the areas are sorted out (Table 4-8). Conical matrix (Table 9) is constructed with the factors at same level of row and column in final reachability matrix.

\section{ISM-based paradigm}

Based on the Table 4-8, the ISM paradigm for key area shown in Figure 1 is formed. From Figure 1, it could be evident that lack of effective management tool is the primary concern area affecting the inventory management (A2) and it forms the base of ISM paradigm. Usage of ineffective management tools combining with poor layout plan (A4) makes the inventory management worse. Export polices (A9) decides the supply chain management and logistic providers. Sometimes changes in export policies leads to over stock in the inventory accounting for huge financial loss. Production system (A1) and employee training (A7) are mutually dependent. Depending on the customer's choice only, the production system is chosen i.e. batch production, lot production or mass production. Unreliable suppliers (A4) are vital component for managing inventory. Lack of coordination, financial constraints, poor demand forecasting and customer service forms the top of ISM paradigm. Demand forecasting (A6) should be analyzed correctly as it changes seasonally.

\section{E. MICMAC Analysis}

MICMAC analysis was carried based on ISM paradigm. The factors are categorized under four areas - autonomous, dependent, linkage and independent areas. Influencing and dependence power of concern areas obtained in final reachability matrix is used in MICMAC analysis. The characteristics of four areas are detailed as follows: Autonomous area - have weak influence power and dependence, Dependent area - have weak influence power but strong dependence, Linkage area - have strong influence power and dependence, Independent area - have strong influence power but weak dependence. Fig. 2 displays influencing power dependence diagram of concern areas affecting inventories.

\section{RESULT AND DISCUSSIONS}

In this work, key concern areas identified in inventory management have been evaluated using ISM model. MICMAC analysis is used to understand the relative significance and the interconnections among the key concern areas which will assist the mangers in handling the inventory issues. Depending on the ISM-based paradigm, sequence of actions has to be taken to overcome the difficulty in inventory management. ISM-based

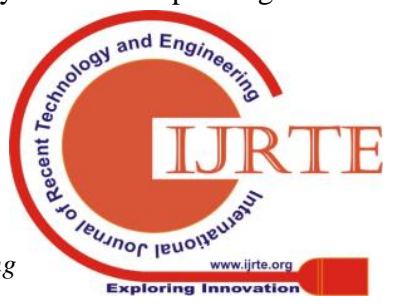


model shows that the key concern areas - lack of coordination, financial constraints, customer service and demand forecasting are at Level I and have strong influence power and dependence. Absence of autonomous key concern areas indicates that all the key concern areas considered influences the inventory management are significant. The other key concern areas are categorized in different levels as below:

- Level II: Unreliable suppliers

- Level III: Production system \& employee training

- Level IV: Export policies

- Level V: Proper Layout Design

- Level VI: Effective Management Tools

Effective management tool categorized under level VI occupies the bottom of the ISM hierarchical model. Effective management tool, have strong driving power with weak dependence. Lack of coordination and financial constraints have strong driving power and dependence. From MICMAC analysis, it should be noted that out of ten areas eight areas falls under the linkage area. These eight areas are unsteady and have strong driving power and dependence. Two areas- effective management and proper layout design falls under independent area. The two areas have strong driving power and weak dependence power. Ravi and Shankar [16] in their work stated that factors with strong driving power as key factors. Hence all the evaluated key concern areas can be called as key factors in inventory management.

\section{MANAGERIAL IMPLICATIONS}

The following managerial insights are made depending on ISM and MICMAC results:

- Absence of autonomous variables specifies that all the key concerned areas are vital for effective inventory management. Autonomous categories have weak influences and weak dependence.

- Effective management tool, lack of coordination and financial constraints are identified as the prime concern areas which needs immediate attention. Prioritization and corrective action must be taken to avoid these problems.

- Eight areas falling under linkage category are most influential in inventory management. These areas are unsteady and have strong dependence power. Any modification in this area will affect other area.

\section{CONCLUSION}

The leather garment industry visited for the work was facing huge loss over the years due to poor inventory management. Through literature survey and interaction with industrial experts, ten key concern areas are identified as major trouble causers in inventory management. Using ISM technique, the relationship among the key concern areas is established. From ISM paradigm, it could be seen that lack of coordination, demand forecasting, employee training, financial constraints and customer service is at Level I. The remaining areas occupy their respective position. It should be observed that effective management tool occupies the bottom of ISM paradigm. The bottom of the ISM paradigm needs immediate attention and proactive actions must be taken to prevent worsen case. MICMAC analysis is carried out to understand the interdependence among identified areas. Absence of autonomous areas in MICMAC analysis implies the significance of all concern areas in inventory management. In this study, the interdependencies of the identified key concern areas are analyzed by ISM model and MICMAC analysis based on the suggestions of industrial experts and literature surveys. Statically validating the robustness of the results will be the future scope of the work.

\section{REFERENCES}

1. M. Hart, M. Tomaštík and P. Taraba, "Inventory management system of a company the methodics to design," Research in Logistics \& Production, Vol. 4(4), 2014, 293-305.

2. J. Korpela and M. Tuominen,"Inventory forecasting with a multiple criteria decision tool," International journal of production economics, Vol. 45(1-3), 1996, 159-168.

3. A. Angulo, H. Nachtmann and M. A. Waller, "Supply chain information sharing in a vendor managed inventory partnership," Journal of business logistics, Vol. 25(1), 2014, 101-120.

4. G. Kabir and M. A. A. Hasin, "Comparative analysis of AHP and fuzzy AHP models for multicriteria inventory classification," International Journal of Fuzzy Logic Systems, Vol. 1(1), 2011, 1-16.

5. B.D. Williams and T. Tokar, "A review of inventory management research in major logistics journals: Themes and future directions," The International Journal of Logistics Management, Vol. 19(2), 2008, 212-232.

6. S. W. Chan, R. Tasmin, A. N. Aziati, R. Z. Rasi, F. B. Ismail and L. P. Yaw, "Factors Influencing the Effectiveness of Inventory Management in Manufacturing SMEs," In IOP Conference Series: Materials Science and Engineering, Vol. 226, No. 1, 2017, p. 012024. IOP Publishing.

7. H. Shen, Q. Deng, R. Lao and S. Wu, "A case study of inventory management in a manufacturing company in China," Nang Yan Business Journal, Vol. 5(1), 2016, 20-40.

8. G. Hua, T. C. E. Cheng and S. Wang, "Managing carbon footprints in inventory management," International Journal of Production Economics, Vol. 132(2), 2011, 178-185.

9. H. Ishii and T. Nose, "Perishable inventory control with two types of customers and different selling prices under the warehouse capacity constraint," International Journal of Production Economics, Vol. 44(1-2), 1996, 167-176.

10. T. C. Jones and D. W. Riley, "Using inventory for competitive advantage through supply chain management," Internationa Journal of Physical Distribution \& Materials Management, Vol. 15(5), 1985, 16-26.

11. P. Jonsson and S. A. Mattsson, "Inventory management practices and their implications on perceived planning performance," International journal of production research, Vol. 46(7), 2008, 1787-1812.

12. D. P. Koumanakos, "The effect of inventory management on firm performance," International journal of productivity and performance management, Vol. 57(5), 2008, 355-369.

13. Z. Momeni and A. Azizi, "Current Order and Inventory Models in Manufacturing Environments: A Review from 2008 to 2018," International Journal of Online Engineering (iJOE), Vol. 14(06), 2018, 223-248

14. R. Tiwari, "Identification of factors affecting reverse chain performance in relation to customer satisfaction using ISM modelling \& MICMAC analysis," Uncertain Supply Chain Management, Vol. 1(4), 2013, 237-252.

15. J. P. George and V. R. Pramod, "An interpretive structural model (ISM) analysis approach in steel re rolling mills (SRRMS)," International Journal of Research in Engineering \& Technology (IMPACT: IJRET), Vol. 2(4), 2014, 161-174.

16. K. Mathiyazhagan, K. Govindan, A. NoorulHaq and Y. Geng, "An ISM approach for the barrier analysis in implementing green supply chain management," Journal of Cleaner Production, Vol. 47, 2013 283-297.

17. V. Ravi and R. Shankar, "Analysis of interactions among the barriers of reverse logistics," Technological Forecasting and Social Change, Vol. 72(8), 2005, 1011-1029.

18. Y. Li, B. Sankaranarayanan, D. T. Kumar and A. Diabat, "Risks assessment in thermal power plants using ISM methodology," Annals of Operations Research, 2019, 1-25 


\section{AUTHORS PROFILE}

K.Koppiahraj obtained his B.E (MECH) in 2014 from the Erode sengunthar engineering college, Erode, Tamilnadu, India. He completed his M.Tech (CAD/CAM) in 2016 at the B.S.Abdur Rahman Crescent institute of science and technology, Chennai, Tamilnadu, India. Currently, he is a Research Scholar in the Department of Mechanical Engineering, Kalasalingam Academy of Research and Education, Krishnankoil, Tamilnadu, India. His research interests include multi-criteria decision making and application of fuzzy set theory in real life decision problems. He is currently pursuing PHD in the area of analyzing Day-today challegnes in leather industries using MCDM techniques.

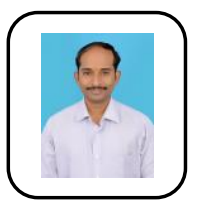

Dr.S.Bathrinath is an Associate Professor in the Department of Mechanical Engineering, Kalasalingam Academy of Research and Education, Krishnankoil, Tamilnadu, India. His current area of research includes multi-criteria decision making, scheduling \& optimization, soft computing and Artificial intelligence. He has published a number of papers in journal of national/international repute and presented a number of papers in various conferences/symposia in India and abroad. He is presently guiding a number of master/doctoral research scholars. Dr.S.Bathrinath is the corresponding author and can be contacted at: bathri@gmail.com
Dr.V.G.Venkatesh, a perceptive professional with over 19 years of

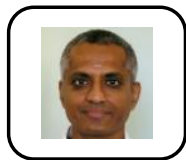
experience with a $\mathrm{PhD}$ in Supply chain and Industry experience from Hong Kong, Bangladesh, Honduras(Central America), and Sri Lanka. Taught in NZ universities (Auckland Uni-Tech and Waikato Management School) and currently teaching in EM Normandie Business School, France (QS and FT ranked - AACSB/EQUIS accredited leading French Business School) and a visiting faculty to reputable institutions across globe. Passionate to share the knowledge with industry professionals. Fields of interests are: Supply chain Management and Operations -Warehousing \& Distribution, Sourcing, International Logistics, Reverse supply chain practices, Materials Management, and Production Planning.

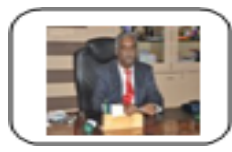
Department of Mechanical Engineering, Kalasalingam Academy of Research and Education, Krishnankoil, Tamilnadu, India. He has more than 20 years of experience in teaching and research. His current area of research includes scheduling, optimization and multi-criteria decision making. He has published more than 40 research articles in journals of national and international repute.

Table- I: Structural Self-Interaction Matrix (SSIM)

\begin{tabular}{|c|c|c|c|c|c|c|c|c|c|c|}
\hline Areas & A 10 & A9 & A8 & A7 & $\mathrm{A} 6$ & A5 & $\mathrm{A} 4$ & $\mathrm{~A} 3$ & A2 & $\mathrm{A} 1$ \\
\hline A 1 & $\mathrm{P}$ & Q & $\mathrm{S}$ & $\mathrm{R}$ & $\mathrm{R}$ & $\mathrm{Q}$ & $\mathrm{P}$ & $\mathrm{Q}$ & $\mathrm{Q}$ & $\mathrm{R}$ \\
\hline $\mathrm{A} 2$ & $\mathrm{P}$ & $\mathrm{S}$ & $\mathrm{S}$ & $\mathrm{P}$ & $\mathrm{P}$ & $\mathrm{Q}$ & $\mathrm{P}$ & $\mathrm{P}$ & $\mathrm{R}$ & \\
\hline A3 & $\mathrm{R}$ & $\mathrm{O}$ & $\mathrm{S}$ & $\mathrm{S}$ & $\mathrm{S}$ & $\mathrm{P}$ & $\mathrm{P}$ & $\mathrm{R}$ & & \\
\hline A4 & $\mathrm{Q}$ & $\mathrm{S}$ & $\mathrm{R}$ & $\mathrm{S}$ & $\mathrm{Q}$ & $\mathrm{R}$ & $\mathrm{R}$ & & & \\
\hline A5 & $\mathrm{P}$ & $\mathrm{R}$ & $\mathrm{O}$ & $\mathrm{R}$ & $\mathrm{R}$ & $\mathrm{R}$ & & & & \\
\hline A6 & $\mathrm{P}$ & $\mathrm{Q}$ & $\mathrm{R}$ & $\mathrm{Q}$ & $\mathrm{R}$ & & & & & \\
\hline A7 & $\mathrm{R}$ & $\mathrm{S}$ & $\mathrm{S}$ & $\mathrm{R}$ & & & & & & \\
\hline A8 & $\mathrm{R}$ & $\mathrm{R}$ & $\mathrm{R}$ & & & & & & & \\
\hline A9 & $\mathrm{Q}$ & $\mathrm{R}$ & & & & & & & & \\
\hline $\mathrm{A} 10$ & $\mathrm{R}$ & & & & & & & & & \\
\hline
\end{tabular}

Table- II. Initial reachability matrix

\begin{tabular}{|c|c|c|c|c|c|c|c|c|c|c|}
\hline Areas & A1 & A2 & A3 & A4 & A5 & A6 & A7 & A8 & A9 & A10 \\
\hline A1 & 1 & 0 & 0 & 1 & 0 & 1 & 1 & 0 & 0 & 1 \\
\hline A2 & 1 & 1 & 1 & 1 & 0 & 1 & 1 & 0 & 0 & 1 \\
\hline A3 & 1 & 0 & 1 & 1 & 1 & 0 & 0 & 0 & 0 & 1 \\
\hline A4 & 0 & 0 & 0 & 1 & 1 & 0 & 0 & 1 & 0 & 0 \\
\hline A5 & 1 & 1 & 0 & 1 & 1 & 1 & 1 & 0 & 1 & 1 \\
\hline A6 & 1 & 0 & 0 & 1 & 1 & 1 & 0 & 1 & 0 & 1 \\
\hline A7 & 1 & 0 & 0 & 0 & 1 & 1 & 1 & 0 & 0 & 1 \\
\hline A8 & 0 & 0 & 0 & 1 & 0 & 1 & 0 & 1 & 1 & 1 \\
\hline A9 & 1 & 0 & 0 & 0 & 1 & 1 & 0 & 1 & 1 & 0 \\
\hline A10 & 0 & 0 & 1 & 1 & 0 & 0 & 1 & 1 & 1 & 1 \\
\hline
\end{tabular}


Table- III. Final Reachability Matrix

\begin{tabular}{|c|c|c|c|c|c|c|c|c|c|c|c|}
\hline Areas & A1 & A2 & A3 & A4 & A5 & A6 & A7 & A8 & A9 & A10 & $\begin{array}{c}\text { Influence } \\
\text { power }\end{array}$ \\
\hline A1 & 1 & 0 & 0 & 1 & $1^{*}$ & 1 & 1 & $1^{*}$ & 0 & 1 & 7 \\
\hline A2 & 1 & 1 & 1 & 1 & $1^{*}$ & 1 & 1 & $1^{*}$ & 0 & 1 & 9 \\
\hline A3 & 1 & 0 & 1 & 1 & 1 & 0 & $1^{*}$ & $1^{*}$ & $1^{*}$ & 1 & 8 \\
\hline A4 & 0 & 0 & 0 & 1 & 1 & $1^{*}$ & 0 & 1 & $1^{*}$ & $1^{*}$ & 6 \\
\hline A5 & 1 & 1 & 0 & 1 & 1 & 1 & 1 & $1^{*}$ & 1 & 1 & 9 \\
\hline A6 & 1 & 0 & 0 & 1 & 1 & 1 & $1^{*}$ & 1 & 0 & 1 & 7 \\
\hline A7 & 1 & 0 & 0 & $1^{*}$ & 1 & 1 & 1 & 0 & 0 & 1 & 6 \\
\hline A8 & 0 & 0 & 0 & 1 & $1^{*}$ & 1 & 0 & 1 & 1 & 1 & 6 \\
\hline A9 & 1 & 0 & 0 & $1^{*}$ & 1 & 1 & 0 & 1 & 1 & $1^{*}$ & 7 \\
\hline A10 & $1^{*}$ & 0 & 1 & 1 & $1^{*}$ & $1^{*}$ & 1 & 1 & 1 & 1 & 9 \\
\hline $\begin{array}{c}\text { Dependence } \\
\text { power }\end{array}$ & 8 & 2 & 3 & 10 & 10 & 9 & 7 & 9 & 6 & 10 & \\
\hline
\end{tabular}

Table- IV: Trial 1

\begin{tabular}{|c|c|c|c|c|}
\hline Areas & Reachability set & Antecedent set & Intersection set & Level \\
\hline A1 & $1,4,5,6,7,8,10$ & $1,2,3,5,6,7,9,10$ & $1,5,6,7,10$ & \\
\hline A2 & $\begin{array}{c}1,2,3,4,5,6,7,8,1 \\
0\end{array}$ & 2,5 & 2,5 & \\
\hline A3 & $1,3,4,5,7,8,9,10$ & $2,3,10$ & 3,10 & \\
\hline A4 & $4,5,6,8,9,10$ & $\begin{array}{c}1,2,3,4,5,6,7,8,9,1 \\
0\end{array}$ & $4,5,6,7,8,9,10$ & \\
\hline A5 & $1,2,4,5,6,7,8,9,1$ & $1,2,3,4,5,6,7,8,9,1$ & $1,2,4,5,6,7,8,9,1$ & I \\
\hline A6 & 0 & 0 & 0 & I \\
\hline A7 & $1,4,5,6,7,8,10$ & $1,2,4,5,6,7,8,9,10$ & $1,4,5,6,7,8,10$ & \\
\hline A8 & $4,5,6,8,9,10$ & $1,2,3,5,6,7,10$ & $1,5,6,7,10$ & \\
\hline A9 & $1,4,5,6,8,9,10$ & $3,2,3,4,5,6,8,9,10$ & $4,5,6,8,9,10$ & I \\
\hline A10 & $1,3,4,5,6,7,8,9,1$ & $1,2,3,4,5,6,7,8,9,1$ & $1,3,4,5,6,7,8,9,1$ & I \\
\hline
\end{tabular}

Table- V: Trial 2

\begin{tabular}{|c|c|c|c|c|}
\hline Areas & Reachability set & Antecedent set & $\begin{array}{c}\text { Intersection } \\
\text { set }\end{array}$ & Level \\
\hline A1 & $1,4,7$ & $1,2,3,7,9$ & 1,7 & \\
\hline A2 & $1,2,3,4,7$ & 2 & 2 & \\
\hline A3 & $1,3,4,7,9$ & 2,3 & 3 & \\
\hline A4 & 4,9 & $1,2,3,4,7,9$ & 4,9 & II \\
\hline A7 & $1,4,7$ & $1,2,3,7$ & 1,7 & \\
\hline A9 & $1,4,9$ & $3,4,9$ & 4,9 & \\
\hline
\end{tabular}

Table- VI: Trial 3

\begin{tabular}{|c|c|c|c|c|}
\hline Areas & Reachability set & Antecedent set & $\begin{array}{c}\text { Intersection } \\
\text { set }\end{array}$ & Level \\
\hline A1 & 1,7 & $1,2,3,7,9$ & 1,7 & III \\
\hline A2 & $1,2,3,7$ & 2 & 2 & \\
\hline A3 & $1,3,7,9$ & 2,3 & 3 & \\
\hline A7 & 1,7 & $1,2,3,7$ & 1,7 & III \\
\hline A9 & 1,9 & 3,9 & 9 & \\
\hline
\end{tabular}

Table- VII: Trial 4

\begin{tabular}{|c|c|c|c|c|}
\hline Areas & Reachability set & Antecedent set & $\begin{array}{c}\text { Intersection } \\
\text { set }\end{array}$ & Level \\
\hline A2 & 2,3 & 2 & 2 & \\
\hline A3 & 3,9 & 2,3 & 3 & \\
\hline A9 & 9 & 3,9 & 9 & IV \\
\hline
\end{tabular}

Table- VIII: Trial 5

\begin{tabular}{|c|c|c|c|c|}
\hline Areas & Reachability set & Antecedent set & $\begin{array}{c}\text { Intersection } \\
\text { set }\end{array}$ & Level \\
\hline A2 & 2,3 & 2 & 2 & VI \\
\hline A3 & 3 & 2,3 & 3 & V \\
\hline
\end{tabular}

Table- IX: Conical matrix

\begin{tabular}{|c|c|c|c|c|c|c|c|c|c|c|}
\hline Areas & A4 & A7 & A8 & A1 & A6 & A9 & A3 & A2 & A5 & A10 \\
\hline A4 & 1 & 1 & $1^{*}$ & 1 & 1 & 0 & 0 & 0 & $1^{*}$ & 1 \\
\hline A7 & 1 & 1 & $1^{*}$ & 1 & 1 & 0 & 1 & 1 & $1^{*}$ & 1 \\
\hline A8 & 1 & $1^{*}$ & $1^{*}$ & 1 & 0 & $1^{*}$ & 1 & 0 & 1 & 1 \\
\hline A1 & 1 & 0 & 1 & 0 & $1^{*}$ & $1^{*}$ & 0 & 0 & 1 & $1^{*}$ \\
\hline A6 & 1 & 1 & $1^{*}$ & 1 & 1 & 1 & 0 & 1 & 1 & 1 \\
\hline
\end{tabular}




\begin{tabular}{|c|c|c|c|c|c|c|c|c|c|c|}
\hline A9 & 1 & $1^{*}$ & 1 & 1 & 1 & 0 & 0 & 0 & 1 & 1 \\
\hline A3 & $1^{*}$ & 1 & 0 & 1 & 1 & 0 & 0 & 0 & 1 & 1 \\
\hline A2 & 1 & 0 & 1 & 0 & 1 & 1 & 0 & 0 & $1^{*}$ & 1 \\
\hline A5 & $1^{*}$ & 0 & 1 & 1 & 1 & 1 & 0 & 0 & 1 & $1^{*}$ \\
\hline A10 & 1 & 1 & 1 & $1^{*}$ & $1^{*}$ & 1 & 1 & 0 & $1^{*}$ & 1 \\
\hline
\end{tabular}

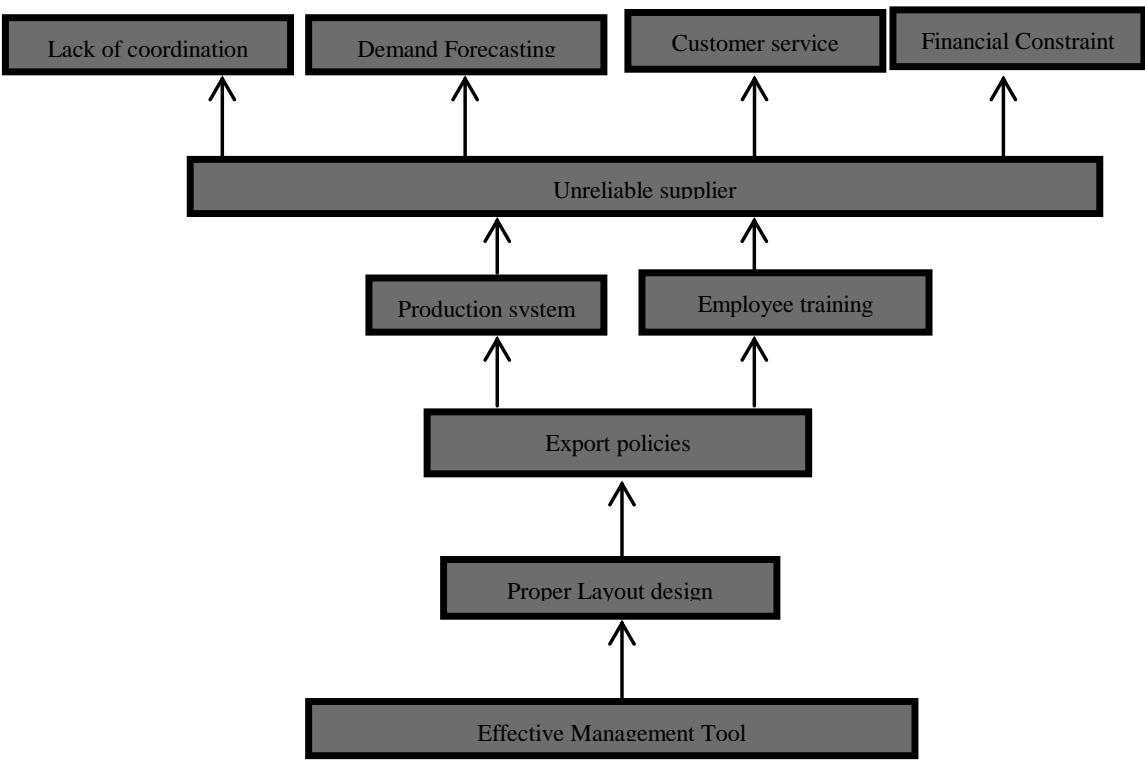

Fig. 1. ISM paradigm for key areas

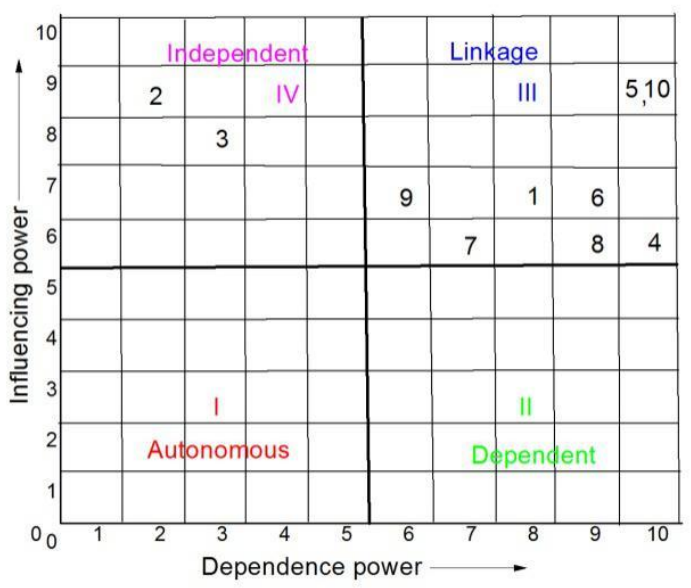

Fig. 2. Influence and Dependence power diagram 